\title{
Experience of Mother on Caring of Children with Low Birth Weight in an Urban Setting, Indonesia: A Descriptive Phenomenological Study
}

\author{
Zubaidah Zubaidah $^{1}$ (D), Yeni Rustina ${ }^{1 *}$ (D), Nani Nurhaeni ${ }^{1}$, Sutanto Priyo Hastono ${ }^{2}$ (D) \\ ${ }^{1}$ Faculty of Nursing, Universitas Indonesia Depok, Jakarta, Indonesia; ${ }^{2}$ Faculty of Public Health, Universitas Indonesia Depok, \\ Jakarta, Indonesia
}

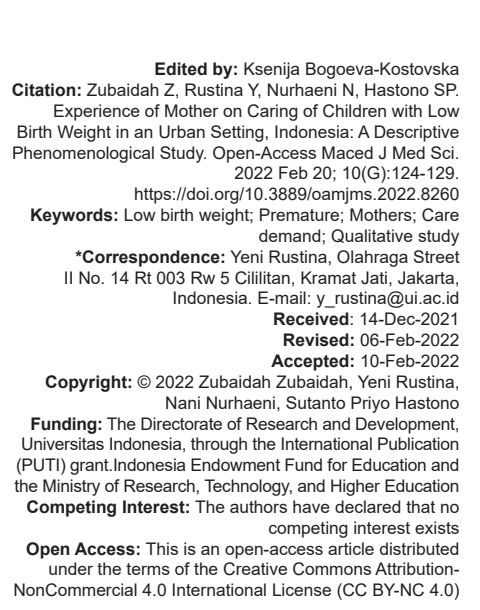

\section{Introduction}

Low birth weight is a major public health issue; it causes $80 \%$ of the 19 deaths per 1000 live births neonatal mortality rate [1], [2]. The prevalence of low birth weight in Indonesia ranged from 1 to $5 \%$ [3]. Birth weight affects child development and survival, having a detrimental effect on people, families, health systems, and national budgets [1], [4]. People who have congenital problems in childhood are more likely to have growth problems, be short or have disabilities, and die after birth [1], [5]. Cognitive and neurodevelopmental deficits, along with adult non-communicable diseases, are likely to cause long-term disability [1], [6].

Indonesia has reaffirmed its commitment to reducing neonatal mortality by focusing on small and ill babies, as outlined in the Sustainable Development Goals, which targets 12 neonatal deaths per 1000 live births by 2030 . These efforts aim to reduce the anticipated 1 million neonatal deaths on delivery, another 1 million within the $1^{\text {st }}$ week, and 2.5 million newborn deaths within the $1^{\text {st }}$ month of life [7]. Poor access to health care and little contact with the health worker after the baby discharged from the hospital make it essential for caregivers to know how to save the baby's life with evidence-based practices at home. The previous studies found that low birth weight mothers had poor awareness caring their babies at home care adequately [8], [9]. Failure to recognize the presence of low birth weight delays care seeking and results in inappropriate caring, including immediate cord clamping and the use of pre-lacteal feeding [8]. There is a greater chance that these behaviors will lead to infections, including sepsis, hypothermia, low blood sugar, and anemia [10]. However, there is a lack of information on the care of low birth weight infants and the impact of care provided on child survival in Indonesia. Therefore, we critically explored mothers caring for children with low birth weight in Indonesia's urban setting in this study. Furthermore, we looked into how society thinks about low birth weight and how mothers think their babies' survival is due to certain things. Thus, this study aimed to explore experience of mothers on caring for children with low birth weight from an urban setting in a low-middle-income country. 


\section{Methods}

Study design: A descriptive phenomenology study was chosen to describe the lived experiences of mothers with low birth weight babies. The study follows the Consolidated Criteria for Reporting Qualitative Studies (COREQ) criteria [11].

\section{Study setting}

The study was conducted at one public health center in Semarang, Central Java, Indonesia, between March and June 2020. Semarang is an urban area as one of the highly populated in Indonesia, with many young people who have relocated from other regions in low-income communities. Many households do not have access to essential social services, and most people in the town are small-time traders. There are several hospitals in the area and a referral center.

\section{Study participants}

Participants were mothers who were at least 18 years old, had a baby with low birth weight, and experienced admitted to and discharged from a perinatology unit. The study did not include women who gave birth to term children and those whose babies experienced admitted to the neonatal intensive care unit. All the eligible participants were obtained from the head nurse of public health center in Semarang. A convenience sample technique was used to select participants.

\section{Data collection procedure}

This study was approved by the Research Ethics Committee of the Faculty of Nursing, Universitas Indonesia (No. SK-251/UN2.F12.D1.2.1/ETIK.FIK.2019). During their clinical visit to the public health center, the mothers were contacted and interviewed. Mothers who expressed an interest were given summary papers outlining the study's goal and nature, as well as written consent forms to sign. After agreeing on a mutually convenient time for interviews, the face-to-face interviews were performed at the participants' homes. The research team utilized a semi-structured interview guide to lead the conversation. A query is as follows: "Could you please tell me about your experiences caring for a preterm/premature infant at home?" Can you explain your experience caring for a low birth weight infant since you returned home from the hospital? The interviews were done by the first and two authors, both females, and lasted 45 min per participant. Audiotapes were used to record the interviews conducted in the Indonesian language. The data collection process took 2 months, and once we reached saturation, we stopped conducting additional interviews.

\section{Data analysis}

We used content analysis to assess the data inductively [12]. The audiotapes were verbatim transcribed. Two authors conducted independent analyses of the phenomenon to minimize personal bias. Line-by-line coding was used to begin the transcription process. The most prevalent and comparable phrases were discovered and coded iteratively. The field notes were consulted and included in the data collection. They were classified into broad categories to organize the codes, then subdivided into themes and subthemes. The data were managed using the NVivo software.

\section{Trustworthiness}

The credibility, confirmability, dependability, and transferability criteria developed by Lincoln et al. [13] were used to establish trustworthiness in this study. To ensure the validity and reliability of the designed themes, member and peer reviews of transcripts were conducted. Dependability and transferability were achieved using extensive field notes and a clear explanation of the research procedure. The COREQ 32-item checklist [11] was also utilized to provide transparent detail of the data collection techniques, and we have included appropriate narratives to increase the credibility of the study. Anonymity was preserved by not revealing mothers' identities in the findings.

\section{Results}

Twenty mothers between the ages of 20 and 37 years were interviewed. Except for two mothers whose husbands worked abroad, they were all married and lived with their spouses. Besides the low birth weight babies, most women had other kids. Five of the 20 mothers said that the low birth weight child was their first child. All participants had completed secondary school. Most of the newborns were intermediate to late preterm (mean age was 35.71 (standard deviation [SD] = 1.63), with gestational ages ranging from 33 to 38 weeks and birth weights ranging from 1.4 to $2 \mathrm{~kg}$. Most newborns were admitted to the perinatology unit for 15-25 days. Their babies age now was 15.34 months $(S D=3.76)$.

The themes and subthemes associated with mothers' experiences of caring for their low birth weight babies at home are outlined in Table 1.

\section{Theme 1: Psychological response of mothers}

Some of the negative emotions expressed by the mothers were related to fear of the unknown outcome of delivery; for instance, losing their babies; 
Table 1: Overview of the theme and subtheme

\begin{tabular}{ll}
\hline Theme & Subtheme \\
\hline Psychological response of & Fear of unknown outcome of delivery \\
mothers & Feeling guilt and being responsible for the \\
& baby being born with low birth weight \\
& Get closer to God \\
Sharing information related & Frequently informed of care procedures \\
to the care procedure & Information about breastfeeding \\
& Information about the kangaroo method \\
& Information about controlling the infant's body \\
& temperature at home \\
Breastfeeding & Breastfeeding was joyful \\
& Breastfeeding was challenging \\
Social support & Family support \\
& Husband support \\
Health-seeking behavior & Friend support \\
& Regular checking babies' body weight \\
& Vaccination \\
\hline
\end{tabular}

and worsening the condition of their babies. These were expressed as:

"The first feeling was a shock, yes, sad, I wanted everything to be normal, and I was very sorry; he was so small, he was put in an incubator."

"I have gone home while my son is still in the hospital. Worried that something might happen to the baby."

Another negative emotional experience was the feeling of guilt and being responsible for the baby being born prematurely. A mother accentuated

"I considered whether my baby was still alive or not, but I had faced all the uncertainty, thus making me very anxious."

"Even I know my child is not like other children and his elder brothers. I still worry that he could not become prone."

In addition, getting closer to God by praying, surrendering and being grateful, thinking positively, and being patient are one of their responses to calm them down.

"I continue to pray and surrender, but I am grateful that my baby can still be saved."

"I always think positively in caring for children and try to be patient."

\section{the care procedure \\ Theme 2: Sharing information related to}

Even though they were frequently informed of procedures to be performed on their babies, women reported that these procedures were not explained, which caused them to become anxious, mainly when they assumed that operations were being performed on their babies due to their worsening condition. Information about breastfeeding, the kangaroo method, controlling the infant's body temperature at home, and materials on hand are provided to parents before leaving the hospital. A mother said:

"The hospital stated that the small infant should not be cold." ( $P 2,37$ years old)
"I was taught how to wash my hands properly and how to wash my hands before holding the baby properly." (P5, 32 years old)

"The nurse advised me to provide breast milk, which is critical." (P4, 20 years old)

\section{Theme 3: Breastfeeding}

Mothers breastfed their babies every $2 \mathrm{~h}$. Breastfeeding was both joyful and challenging during this time. Mothers appreciated breastfeeding because it facilitated mother-baby contact. It's becoming more critical for parents to learn to help their babies with low birth weight grow and develop well. The following are some examples of the experiences that mothers have described:

"When I'm breastfeeding, I interact with my baby and talk many happy stories of having her." (P4, 20 years old)

"I prefer the sensation of my kid sucking more than the sensation of giving him extracted." (P8, 27 years old)

While breastfeeding was pleasurable, some acknowledged some difficulties. These included babies sleeping for extended periods, an inability to suck well, and pain associated with breast milk expression.

"I enjoy breastfeeding even though it hurts because my breasts are full. I wish he were old enough to suck better; l'd be happier with the way he does." (P3, 25 years old)

\section{Theme 4: Social support}

The mothers reported social support from their spouses, families, and friends. For example, husbands were occasionally responsible for caring for other children in the family, allowing the mothers to concentrate exclusively on the newborns. Even though, in Semarang, Indonesia, spouses' participation in domestic responsibilities is not socially acceptable.

"Even no peer groups, but sometimes our friend or midwife is the first one to help. The cadres gather exclusively at the Integrated Service Post." (P2, 37 years old)

"Normally, my mother assists me, but when I am unable to do so, I do things like shower, cook, or leave the house. If he develops a new problem, I will lend a hand." ( $P 5,32$ years old)

"As long as he's at home, my husband is always there to lend a helping hand and invite him to play." (P7, 34 years old)

\section{Theme 5: Health-seeking behavior}

Primary care facilities with essential services are the only places people go to get medical care. Every 
month, mothers take their children to integrated health posts to check their babies weighed and counseled. The mother also went to the health center to get vaccinated.

"I went to the integrated health post every month to check my baby's body weight and the head circumference." (P8, 27 years old)

"...but I usually go to a public health center near home for vaccination." (P1, 31 years old)

\section{Discussion}

Caring for babies with low birth weight has been described as stressful. Mothers in this study exhibited a range of emotions, including anxiety, joy, and guilt, which corroborated with Arnold [14]. The unintended childbirth of a low birth weight infant elicits both immediate and long-term emotional responses [15]. This is due to a lack of knowledge and competence to care for preterm newborns after discharge and their infants' additional health demands [16], [17]. Similar to the previous research, mothers felt terrible about having a low birth weight baby [18], [19], [20]. These maternal emotional reactions can negatively impact maternal health and the mother-infant bond [21]; health professionals should provide emotional support to these mothers.

Similar to Amankwaa et al. findings, breastfeeding allowed moms to hug, talk to, play with, and smile at their newborns [22]. According to Giann et al. [23], mothers did not stop breastfeeding their babies because of problems with sucking and drowsiness. They thought that breastfeeding would be an opportunity to be close to the baby, bond with them, and enjoy motherhood [24]. Moreover, participants in this study believed that health workers did not communicate well with them or provide them time to ask any questions about the baby's condition or treatment. The previous studies in developed countries have hinted that they found the same thing: Women caring for low birth weight babies in the perinatology unit wanted to be listened to and have formal talks with health professionals [25], [26]. The high patient load and low staffing levels in public health may be contributing to the communication issue [27]. Giving the correct information to mothers who have low birth weight babies can help them make better decisions about their health [28]. Mothers require information to properly care for their infants, including routine care and how to handle unexpected circumstances [29]. The discharge education program will improve the mother's understanding of her child's condition [30]. Before discharge from the perinatology unit, they must have a comprehensive knowledge and understanding of all critical information and instructions to avoid forgetting new instructions given until the day of their return home when they feel stressed [31].

The previous research has acknowledged the importance of community-based programs to enhance the understanding of low birth weight babies and enable mothers to care for them at home [32], [33], [34]. Community education must be strengthened with culturally relevant content targeted to eliminate negative stereotypes [34]. Support groups for low birth weight babies can be established as a preventative step to promote a positive reconception of these babies. Community support groups can use cultural brokering to facilitate better communication between mothers and health-care providers and the more extensive social network.

\section{Limitations}

This study has several limitations. First, the research was conducted in a one public health center in Indonesia, which might limit the generalizability of study findings. Second, we could not contact many potential participants because they lived outside of Semarang and had different issues. Nonetheless, this study employed in-depth interviews, reflecting broader experiences caring for low birth weight infants at home.

\section{Conclusions}

This study provides insights into the body of knowledge about how Indonesian mothers care for their low birth weight babies in the $1^{\text {st }}$ month after discharge from perinatology. In addition to cultural traditions and familial factors, further study should evaluate the impact of these on outcomes for women caring for low birth weight infants following hospital discharge. Mothers with low birth weight babies require a more extensive and practical education customized to their specific needs to boost their confidence and encourage a more positive experience with their newborns. Social support systems must be established and reinforced as a critical resource for mothers during the $1^{\text {st }}$ year after delivery. Mothers should be encouraged to encourage happier motherhood.

\section{Acknowledgments}

We would like to thank the Indonesia Endowment Fund for Education and the Ministry 
of Research, Technology, and Higher Education (201710210411751) for providing financial support for this study. We also thank the Directorate of Research and Development, Universitas Indonesia, for publication support through the International Publication grant (No: NKB-3200/UN2.RST/ HKP.05.00/2020).

\section{References}

1. Lawn JE, Blencowe H, Oza S, You D, Lee AC, Waiswa P, et al. Every newborn: Progress, priorities, and potential beyond survival. Lancet. 2014;384(9938):189-205. https://doi. org/10.1016/S0140-6736(14)60496-7

PMid:24853593

2. UNICEF GHANA. World Prematurity Day 2015. Ghana: UNICEF GHANA; 2015.

3. Pristya TY, Novitasari A, Hutami MS. PNovitasari, and M. S. Hutami, "Prevention and Control of LBW in Indonesia: Systematic Review. Indones J Health Dev. 2020;2(3):175-82.

4. Liu L, Johnson HL, Cousens S, Perin J, Scott S, Lawn JE, et al. Global, regional, and national causes of child mortality: An updated systematic analysis for 2010 with time trends since 2000. Lancet. 2012;379(9832):2151-61. https://doi.org/10.1016/ S0140-6736(12)60560-1

PMid:22579125

5. Best KE, Tennant PWG, Rankin J. Survival, by birth weight and gestational age, in individuals with congenital heart disease: A population-based study. J Am Heart Assoc. 2017;6(7):e005213. https://doi.org/10.1161/JAHA.116.005213 PMid:28733436

6. Calkins K, Devaskar SU. Fetal origins of adult disease. Curr Probl Pediatr Adolesc Health Care. 2011;41(6):158-76.

PMid:21684471

7. World Health Organization. Preterm Birth. Geneva: World Health Organization; 2018. Available from: https://www.who. int/news-room/fact-sheets/detail/\%0apreterm-birth\%0a [Last accessed on 2021 Jul 20].

8. Ayiasi RM, Criel B, Orach CG, Nabiwemba E, Kolsteren P. Primary healthcare worker knowledge related to prenatal and immediate newborn care: A cross sectional study in Masindi, Uganda. BMC Health Serv Res. 2014;14:65. https://doi. org/10.1186/1472-6963-14-65

PMid:24511880

9. Darmstadt GL, Walker N, Lawn JE, Bhutta ZA, Haws RA, Cousens S. Saving newborn lives in Asia and Africa: Cost and impact of phased scale-up of interventions within the continuum of care. Health Policy Plan. 2008;23(2):101-17. https://doi. org/10.1093/heapol/czn001

PMid:18267961

10. Marsh DR, Darmstadt GL, Moore J, Daly P, Oot D, Tinker A. Advancing newborn health and survival in developing countries: A conceptual framework. J Perinatol. 2002;22(7):572-6. https:// doi.org/10.1038/sj.jp.7210793 PMid: 12368975

11. Tong A, Sainsbury P, Craig J. Consolidated criteria for reporting qualitative research (COREQ): A 32-item checklist for interviews and focus groups. Int J Qual Health Care. 2007;19(6):349-57. https://doi.org/10.1093/intqhc/mzm042

PMid: 17872937
12. Kim H, Sefcik JS, Bradway C. Characteristics of qualitative descriptive studies: A systematic review. Res Nurs Health. 2017;40(1):23-42. https://doi.org/10.1002/nur.21768 PMid:27686751

13. Lincoln YS, Guba EG, Pilotta JJ. Naturalistic Inquiry Newbury Park. California: Sage; 1985.

14. Arnold L, Sawyer A, Rabe H, Abbott J, Gyte G, Duley L, et al. Parents' first moments with their very preterm babies: A qualitative study. BMJ Open. 2013;3(4):e002487. https://doi. org/10.1136/bmjopen-2012-002487

PMid:23550091

15. Henderson J, Carson C, Redshaw M. Impact of preterm birth on maternal well-being and women's perceptions of their baby: A population-based survey. BMJ Open. 2016;6(10):e012676. https://doi.org/10.1136/bmjopen-2016-012676 PMid:27855105

16. Adama EA, Bayes S, Sundin D. Parents' experiences of caring for preterm infants after discharge from neonatal intensive care unit: A meta-synthesis of the literature. J Neonatal Nurs 2016;22(1):27-51.

17. Jefferies AL, Canadian Paediatric Society, Fetus and Newborn Committee. Going home: Facilitating discharge of the preterm infant. Paediatr Child Health. 2014;19(1):31-6.

PMid:24627654

18. Bernard RS, Williams SE, Storfer-Isser A, Rhine W, Horwitz SM, Koopman C, et al. Brief cognitive-behavioral intervention for maternal depression and trauma in the neonatal intensive care unit: A pilot study. J Trauma Stress. 2011;24(2):230-4. https://doi.org/10.1002/jts.20626

PMid:21438016

19. Lasiuk GC, Comeau T, Newburn-Cook C. Unexpected: An interpretive description of parental traumas' associated with preterm birth. BMC Pregnancy Childbirth. 2013;13 Suppl 1:S13. https://doi.org/10.1186/1471-2393-13-S1-S13

PMid:23445715

20. Taylor LS. Maternal experiences of preterm birth. Infant. 2016;12(2):57-61.

21. Milgrom J, Gemmill AW, Bilszta JL, Hayes B, Barnett B, Brooks J, et al. Antenatal risk factors for postnatal depression: A large prospective study. J Affect Disord. 2008;108(1-2):147-57. https://doi.org/10.1016/j.jad.2007.10.014 PMid:18067974

22. Amankwaa LC, Pickler RH, Boonmee J. Maternal responsiveness in mothers of preterm infants. Newborn Infant Nurs Rev. 2007;7(1):25-30.

23. Giannì $M L$, Bezze $E$, Sannino $P$, Stori $E$, Plevani L, Roggero $P$ et al. Facilitators and barriers of breastfeeding late preterm infants according to mothers' experiences. BMC Pediatr. 2016;16(1):1-8.

24. Kair LR, Flaherman VJ, Newby KA, Colaizy TT. The experience of breastfeeding the late preterm infant: A qualitative study. Breastfeed Med. 2015;10(2):102-6. https://doi.org/10.1089/ bfm.2014.0121

PMid:25647732

25. Sawyer A, Rabe H, Abbott J, Gyte G, Duley L, Ayers S, et al. Parents' experiences and satisfaction with care during the birth of their very preterm baby: A qualitative study. BJOG. 2013;120(5):637-43. https://doi.org/10.1111/1471-0528.12104 PMid:23289929

26. Ward K. Perceived needs of parents of critically ill infants in a neonatal intensive care unit (NICU). Pediatr Nurs. 2001;27(3):281-6. PMid: 12964668

27. Namaganda G, Oketcho V, Maniple E, Viadro C. Making the 
transition to workload-based staffing: Using the workload indicators of staffing need method in Uganda. Hum Resour Health. 2015;13:89. https://doi.org/10.1186/s12960-015-0066-7 PMid:26621251

28. Gaucher N, Payot A. From powerlessness to empowerment: Mothers expect more than information from the prenatal consultation for preterm labour. Paediatr Child Health. 2011;16(10):638-42. https://doi.org/10.1093/pch/16.10.638 PMid:23204904

29. Burnham N, Feeley N, Sherrard K. Parents' perceptions regarding readiness for their infant's discharge from the NICU. Neonatal Netw. 2013;32(5):324-34. https://doi. org/10.1891/0730-0832.32.5.324 PMid:23985470

30. Hariati S, Sutomo R, Lusmilasari L, Febriani AD, Kadar K. Discharge readiness of Indonesian mother with preterm infant in NICU. Enferm Clin. 2020;30:234-7.

31. Phillips-Pula L, Pickler R, McGrath JM, Brown LF, Dusing SC.
Caring for a preterm infant at home: A mother's perspective. J Perinat Neonatal Nurs. 2013;27(4):335-44. https://doi. org/10.1097/JPN.0b013e3182a983be

PMid:24164816

32. Hawes K, McGowan E, O'Donnell M, Tucker R, Vohr B. Social emotional factors increase risk of postpartum depression in mothers of preterm infants. J Pediatr. 2016;179:61-67. https:// doi.org/10.1016/j.jpeds.2016.07.008

PMid:27502105

33. Adu-Bonsaffoh K, Oppong SA, Dassah ET, Seffah JD. Challenges in preterm birth research: Ghanaian perspective. Placenta. 2020;98:24-8. https://doi.org/10.1016/j.placenta.2020.04.016 PMid:33039028

34. Adama EA, Sundin D, Bayes S. Sociocultural practices affecting the care of preterm infants in the Ghanaian community. J Transcult Nurs. 2021;32(5):458-65. https://doi. org/10.1177/1043659620975098

PMid:33225863 